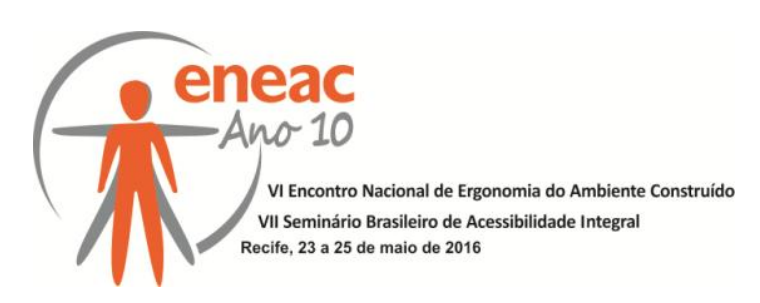

\title{
APLICABILIDADE DA NBR 15575 À HABITAÇÃO DE INTERESSE SOCIAL QUANTO À FUNCIONALIDADE E ACESSIBILIDADE DAS ÁREAS PRIVATIVAS HABITACIONAIS - ESTUDO DE CASO: PORTO VELHO, RO
}

\author{
SANTOS, Mayara Jordana Barros Oliveira(1); \\ OLIVEIRA, Valéria Costa de (2); \\ SPOSTO, Rosa Maria (3)
}

(1) Universidade de Brasília, Mestranda, aluna do Programa de Pós-Graduação em

Estruturas e Construção Civil

e-mail:mayjordana@gmail.com

(2) Universidade de Brasília, Mestranda, aluna do Programa de Pós-Graduação em

Estruturas e Construção Civil

e-mail:valeria.oliveira@ifro.edu.br

(3) Universidade de Brasília, Doutora, professora do Programa de Pós-Graduação em

Estruturas e Construção Civil

e-mail:rmsposto@unb.br

\begin{abstract}
RESUMO
As dimensões da habitação destinada à população de baixa renda compromete o desempenho exigido para edificações pela Norma Técnica ABNT NBR 15575, pois são projetadas desvinculadas da adequada funcionalidade e acessibilidade. A partir de análise de Projetos arquitetônicos de habitações de interesse social no Município de Porto Velho - RO e da indicação do mobiliário e equipamento mínimo requerido na ABNT NBR 15575, possibilitou-se identificar as não conformidades das dimensões disponibilizadas pela unidade habitacional. A elaboração e aplicação de um check list identificou os conflitos espaciais com as exigências da norma de desempenho ABNT NBR 15575 e ABNT NBR 9050.
\end{abstract}

Palavras chave: acessibilidade; funcionalidade; cadeirante.

\begin{abstract}
The dimensions of the house intended for low-income population compromises the performance required for buildings by the Technical Standard NBR 15575 as they are designed unrelated proper functionality and accessibility. From analysis of architectural projects of social housing in the city of Porto Velho - RO and the furniture and display minimum requirement in ISO 15575, made it possible to identify non-compliance of the dimensions provided by the housing unit. The development and implementation of a checklist identified the spatial conflicts with the requirements of the performance standard NBR 15575 and NBR 9050.
\end{abstract}

Keywords: accessibility; functionality; wheelchair. 


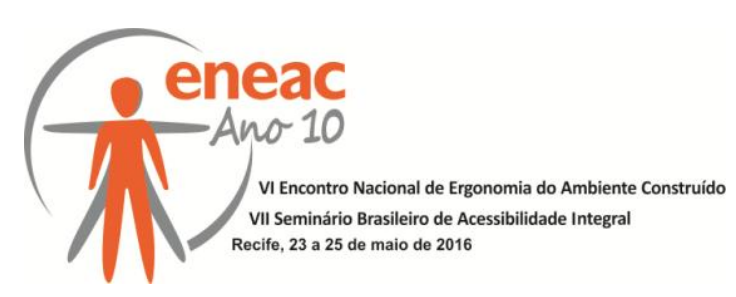

\section{INTRODUÇÃO}

A tendência de redução das dimensões da habitação destinada à população de baixa renda compromete o desempenho exigido para edificações pela Norma Técnica ABNT NBR 15575-1, pois os ambientes são projetados com dimensões desvinculadas das exigências espaciais para a adequada funcionalidade e acessibilidade.

A habitação é produto complexo em razão de suas atribuições e multiplicidade de funções que desempenha, e sua complexidade é devida à dimensão que assume na vida do ser humano (MARTINS et al, 2007). O usuário do espaço não é só representado pelo indivíduo que goza da perfeição física e saúde inabalável, com pleno desempenho das suas capacidades e habilidades, mas também por aqueles com diferenças em suas condições físicas, limitados na execução de suas atividades, as pessoas portadoras de necessidades em geral (FREGOLENTE, 2008).

A redução das dimensões da habitação de interesse social (HIS) compromete a qualidade espacial, pois os ambientes são projetados com dimensões desvinculadas das exigências espaciais para a adequada execução das tarefas cotidianas. A necessidade da melhoria da qualidade espacial dos projetos torna prioritária a concepção de unidades habitacionais com dimensões voltadas para a funcionalidade e conforto dos usuários (DAMÉ, 2008).

Em relação à normalização, no ano de 2013 entrou em vigor a norma de desempenho ABNT NBR 15575, destinada a edificações habitacionais, com requisitos e critérios de segurança, habitabilidade e sustentabilidade, e no mês de outubro ano de 2015, a ABNT NBR 9050 foi atualizada, destinada a Acessibilidade a edificações, mobiliário, espaços e equipamentos urbanos. Na produção de edificações na fase de projeto, em geral, não há grande preocupação de especificar espaços adaptados a pessoas com deficiências físicas. No entanto, a evolução das exigências das legislações, incluindo código de defesa do consumidor, que veda ao fornecedor de colocar no mercado qualquer serviço ou produto no mercado em desacordo com as normas técnicas brasileiras, observou-se a necessidade de modificação do ambiente construído (CALDAS et al, 2014).

A ABNT NBR 15575 tem o objetivo de estabelecer parâmetros e quantitativos que podem ser medidos. Traz algumas novidades como o conceito de comportamento em uso dos componentes e sistemas das edificações, sendo que as edificações habitacionais devem atender e cumprir as exigências dos usuários ao longo dos anos, promovendo a melhoria da relação de consumo do mercado imobiliário, através do envolvimento e definição de responsabilidades de todos os envolvidos: projetistas, fornecedores de materiais, componente e/ou sistema, construtor, incorporador e usuário. Desta forma, além dos aspectos de desempenho estrutural, segurança contra incêndios, durabilidade e outros, é necessário que a edificação habitacional atenda aos requisitos e critérios de funcionalidade e acessibilidade (CBIC, 2013).

O anexo G (informativo) da ABNT NBR 15575-1/2013 visa apresentar como sugestão algumas das possíveis formas de organização dos cômodos e dimensões compatíveis com as necessidades humanas. Recomenda-se que os projetos de arquitetura de edifícios habitacionais prevejam no mínimo a disponibilidade de espaço nos cômodos do edifício habitacional para colocação e utilização dos móveis e equipamentos-padrão.

A ABNT NBR 9050 trata da adequação das edificações e do mobiliário urbano. A primeira versão desta norma foi divulgada em setembro de 1994. Como o foco são edificações habitacionais, essas podem ser classificadas como unifamilares ou multifamiliares. Também estão sujeitos aos preceitos da acessibilidade aos acessos, piscinas, andares, recreação, salão de festas e reuniões, saunas e banheiros, quadras esportivas, estacionamentos e garagens, entre outras partes internas ou externas de uso comum das edificações de uso privado multifamiliar. Os parâmetros básicos para a concepção de uma edificação acessível 


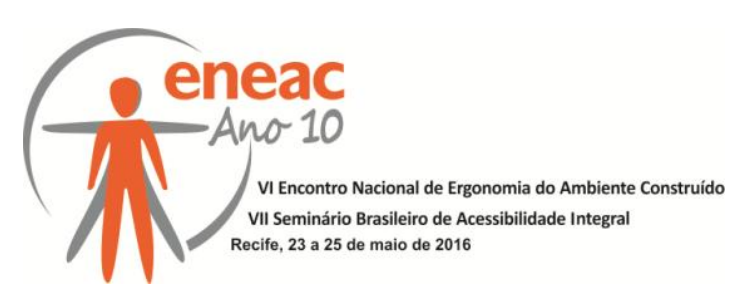

deverão ser trabalhados em conjunto, garantindo a plena acessibilidade das edificações através de rotas acessíveis.

Conforme a Portaria no 595, de 18 de dezembro de 2013, que dispõe sobre os parâmetros de priorização e sobre o processo de seleção dos beneficiários do Programa Minha Casa, Minha Vida - PMCMV, será assegurado que, do total de unidades habitacionais do empreendimento, pelo menos 3\% (três por cento) serão destinadas ao atendimento a pessoa com deficiência ou à famílias de que façam parte pessoas com deficiência, na ausência de percentual superior fixado em legislação municipal ou estadual.

Além das diretrizes estabelecidas nas normas pertinentes deve-se também, na hora de projetar, estudar o código de obras da cidade em que será construída a edificação. No que diz respeito ao seu código de obras do município de Porto Velho - RO, conforme lei complementar no 560, de 23 de dezembro de 2014, em breves parágrafos sobre habitações ele encaminha o projetista para o atendimento a norma de desempenho e recomenda que sejam levadas em consideração todas as necessidades dos usuários.

O presente trabalho tem como objetivo geral a avaliação dos critérios, levando em consideração o usuário cadeirante, apresentados no anexo G da ABNT NBR 15575-1/2013, que trata especificamente da funcionalidade e acessibilidade dos espaços edificados a serem habitados. Através dos estudos de caso de HIS no município de Porto Velho - RO, os objetivos específicos são:

- Análise dos projetos arquitetônicos e comparar as exigências de funcionalidade previstas nas normas ABNT NBR 15575-1 e ABNT NBR 9050 e no código de obras da cidade e verificar o seu cumprimento nas edificações em estudo;

- Agrupar os requisitos quanto à acessibilidade e funcionalidade dos cadeirantes em áreas privativas conforme a norma de desempenho no formato de um check-list, para facilitar o processo de verificação dos mesmos.

\section{ARRANJOS FíSICOS DE HABITAÇÕES ACESSÍVEIS}

A forma de apropriação familiar em uma habitação acessível gera acessibilidade para a pessoa com deficiência, a universalização do uso do espaço acessível projetado para a moradia popular, considerando o modo de vida do morador com ou sem deficiência aparente, gera qualidade de uso na habitação e a habitação acessível, caracterizada por maior área construída, implica em um número maior de pessoas que coabitam e em maior número de barreiras físicas (LEÃO, 2011).

É importante que habitações sejam projetadas obedecendo a critérios mínimos para o mobiliário e equipamentos, bem como o seu arranjo para circulação e utilização, de modo a se obter uma boa aceitação por parte dos usuários (MARTINS et al, 2007).

Os benefícios dessas transformações refletem-se também na habitação, especialmente quando propõe-se a implementação do Desenho Universal na HIS. Uma habitação com Desenho Universal pode ser utilizada por todas as pessoas, inclusive indivíduos com deficiência e mobilidade reduzida, e permite adequações. Ou seja, prevê vedações verticais preparadas para suportar uma eventual instalação de barras, se necessário; possibilita o reposicionamento de divisórias, propiciando a ampliação de um dormitório, sem implicações ou comprometimentos estruturais, entre outros itens (CDHU - SP, 2010). 


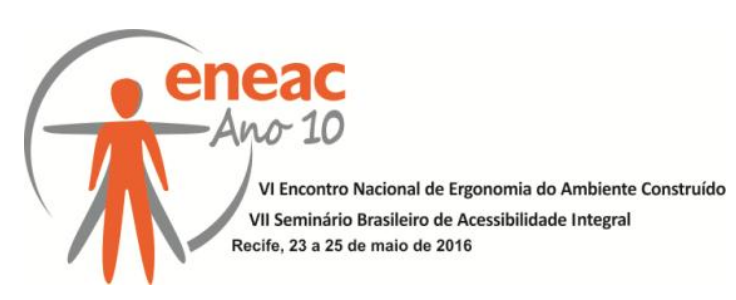

\section{METODOLOGIA}

A metodologia utilizada no trabalho consistiu em uma pesquisa bibliográfica e exploratória. A pesquisa bibliográfica foi realizada por meio de consultas na ABNT NBR 9050 (2015), na ABNT NBR 15575 (2013), código de obras no município de Porto Velho, artigos, dissertações, teses e trabalhos de secretarias estaduais. Foi realizado um levantamento dos requisitos a serem cumpridos nas áreas privativas das edificações, conforme a norma de desempenho (anexo G da ABNT NBR 15575-1), a fim de atender as necessidades de funcionalidade e acessibilidade de pessoas cadeirantes em HIS.

\subsection{Caracterização dos Estudos de Caso}

A segunda etapa da pesquisa, a fase exploratória, consistiu no levantamento e análise de projetos de HIS localizadas no Município de Porto Velho - RO. Foram analisados projetos de cinco edificações.

Tabela 1 - Caracterização dos estudos de caso.

\begin{tabular}{|c|c|c|c|c|}
\hline EDIFICAÇÃO & TIPOLOGIA & $\begin{array}{c}\text { ÁREA DE } \\
\text { CONSTRUÇÃO }\end{array}$ & AMBIENTES & $\begin{array}{c}\text { SISTEMA } \\
\text { CONSTRUTIVO }\end{array}$ \\
\hline$A$ & $\begin{array}{l}\text { Unifamiliar } \\
\text { Geminada }\end{array}$ & 32,46 & $\begin{array}{c}\text { Sala, cozinha, } \\
\text { banheiro, quarto } \\
\text { casal, ampliação } \\
\text { para um quarto }\end{array}$ & $\begin{array}{l}\text { Alvenaria sem } \\
\text { função } \\
\text { estrutural de } \\
\text { tijolos e blocos } \\
\text { cerâmicos }\end{array}$ \\
\hline B & Multifamiliar & 41,39 & $\begin{array}{c}\text { Sala estar/jantar, } \\
\text { cozinha, } \\
\text { banheiro, quarto } \\
\text { casal e quarto } \\
\text { duas pessoas }\end{array}$ & $\begin{array}{c}\text { Alvenaria } \\
\text { estrutural de } \\
\text { blocos vazados } \\
\text { de concreto }\end{array}$ \\
\hline C & $\begin{array}{l}\text { Unifamiliar } \\
\text { Geminada }\end{array}$ & 40,80 & $\begin{array}{c}\text { Sala estar/jantar, } \\
\text { cozinha, } \\
\text { banheiro, quarto } \\
\text { casal e quarto } \\
\text { duas pessoas }\end{array}$ & $\begin{array}{l}\text { Alvenaria sem } \\
\text { função } \\
\text { estrutural de } \\
\text { tijolos e blocos } \\
\text { cerâmicos } \\
\end{array}$ \\
\hline $\mathrm{D}$ & $\begin{array}{l}\text { Unifamiliar } \\
\text { Geminada }\end{array}$ & 36,84 & $\begin{array}{c}\text { Sala estar/jantar, } \\
\text { cozinha, } \\
\text { banheiro, quarto } \\
\text { casal e quarto } \\
\text { duas pessoas }\end{array}$ & $\begin{array}{c}\text { Alvenaria } \\
\text { estrutural de } \\
\text { blocos vazados } \\
\text { de concreto }\end{array}$ \\
\hline$E$ & $\begin{array}{l}\text { Unifamiliar } \\
\text { Geminada }\end{array}$ & 41,74 & $\begin{array}{c}\text { Sala estar/jantar, } \\
\text { cozinha, } \\
\text { banheiro, quarto } \\
\text { casal e quarto } \\
\text { duas pessoas }\end{array}$ & $\begin{array}{l}\text { Paredes } \\
\text { estruturais de } \\
\text { Concreto } \\
\text { Armado }\end{array}$ \\
\hline
\end{tabular}




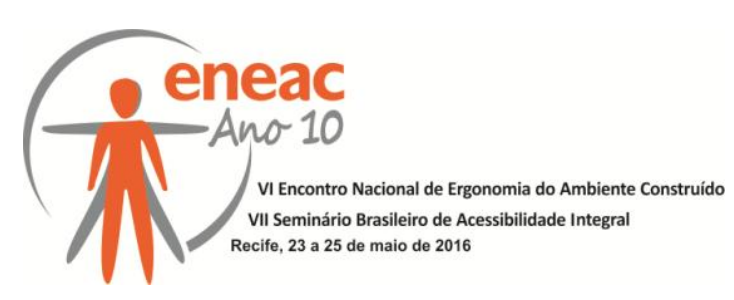

\subsection{Definição do Mobiliário}

A classificação das atividades e os mobiliários e equipamentos requeridos foram selecionados conforme o Anexo G (informativo) da ABNT NBR 15575-1/2013 - Dimensões mínimas e organização funcional dos espaços. Dispôs-se nos ambientes do projeto arquitetônico, no melhor arranjo encontrado, o mobiliário mínimo exigido por norma. As dimensões mínimas dos móveis padrões considerados nos estudos de caso estão dispostas na tabela 2. Para efeito de delimitação das análises foi considerado como morador uma pessoa cadeirante.

Tabela 2 - Móveis padrões utilizados nos ambientes

\begin{tabular}{|c|c|c|c|}
\hline \multirow{3}{*}{ Ambiente } & \multicolumn{3}{|c|}{ Mobiliário } \\
\cline { 2 - 4 } & \multirow{2}{*}{ Móvel ou Equipamento } & \multicolumn{2}{|c|}{ Dimensões (m) } \\
\cline { 2 - 4 } & & $\mathbf{L}$ & $\mathbf{P}$ \\
\hline \multirow{2}{*}{ Sala de Estar } & Sofá de 2 lugares com braço & 1,20 & 0,70 \\
\cline { 2 - 4 } & Estante/Armário para TV & 0,50 & 0,80 \\
\hline Sala de Estar/Jantar & Mesa Redonda para 4 lugares & $\mathrm{D}=0,95$ & \\
\hline \multirow{3}{*}{ Cozinha } & Pia & 1,20 & 0,50 \\
\cline { 2 - 4 } & Fogão & 0,55 & 0,60 \\
\cline { 2 - 4 } & Geladeira & 0,70 & 0,70 \\
\hline \multirow{3}{*}{ Dormitório Casal } & Cama de Casal & 1,40 & 1,90 \\
\cline { 2 - 4 } & Criado Mudo x & 0,50 & 0,50 \\
\cline { 2 - 4 } & Guarda-Roupa & 1,60 & 0,50 \\
\hline \multirow{3}{*}{ Dormitório para 2 pessoas } & Camas de Solteiro & 0,80 & 1,90 \\
\cline { 2 - 4 } & Criado Mudo & 0,50 & 0,50 \\
\cline { 2 - 4 } & Guarda-Roupa & 1,50 & 0,50 \\
\hline \multirow{2}{*}{ Banheiro } & Lavatório & 0,39 & 0,29 \\
\cline { 2 - 4 } & Vaso Sanitário & 0,60 & 0,60 \\
\hline \multirow{2}{*}{ Área de Serviço } & Tanque & 0,52 & 0,53 \\
\cline { 2 - 4 } & Máquina de Lavar & 0,60 & 0,65 \\
\hline
\end{tabular}

\subsection{Layouts, Mobiliário e o Módulo de Referência}

Após a classificação de cada mobiliário e equipamento, estes foram desenhados no software AutoCAD. Para cada item de mobiliário ou equipamento existe uma ou várias atividades associadas. A elaboração de layouts, para cada atividade, permite a análise da associação de um conjunto definido de mobiliário e equipamentos, conferindo a possibilidade de dois ou mais arranjos e/ou de mais de uma atividade com os mesmos itens.

Após o levantamento de requisitos das normas pertinentes, foi elaborado um check list baseado na norma de desempenho no que diz respeito a acessibilidade e funcionalidade, com enfoque nas áreas de circulação, que são, conforme a ABNT NBR 9050, o espaço livre de obstáculo, destinado ao uso de todas as pessoas. 


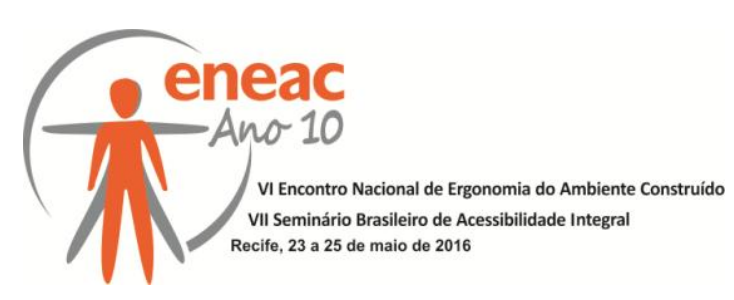

Então, nos estudos de caso aplicou-se o check list, e, através dos layouts definidos, verificou-se as condições de acessibilidade e funcionalidade dos cadeirantes nestas habitações, através do posicionamento do módulo de referência do cadeirante $(0,8 \times 1,20 \mathrm{~m})$ no projeto arquitetônico.

\section{RESULTADOS E DISCUSSÃO}

\subsection{Check List}

O check list (Tabela 3 ) elaborado deve ser aplicado sob posse do projeto arquitetônico da edificação com os móveis mínimos exigidos pelo Anexo G da NBR 15575 - 1/2013 dispostos nos seus respectivos ambientes, conforme o arranjo mais favorecedor ao cumprimento dos requisitos da norma encontrado pelo examinador.

A ABNT NBR 9050 não prevê critérios e requisitos para habitações, mas para locais de hospedagem ela diz que as dimensões do mobiliário dos dormitórios acessíveis devem atender às condições de alcance manual e visual e ser dispostos de forma a não obstruírem uma faixa livre mínima de circulação interna de 0,90 m de largura, prevendo área de manobras para o acesso ao banheiro, camas e armários. Deve haver pelo menos uma área, com diâmetro de no mínimo $1,50 \mathrm{~m}$, que possibilite um giro de $360^{\circ}$, conforme Figura 1 . Em contrapartida esta norma não prevê qualquer exigência quanto a circulação do cadeirante em sua própria moradia após a disposição dos móveis mínimos.

\section{Figura 1 - Dormitório Acessível - área de circulação mínima - Exemplo - Vista Superior. Fonte: ABNT NBR 9050}

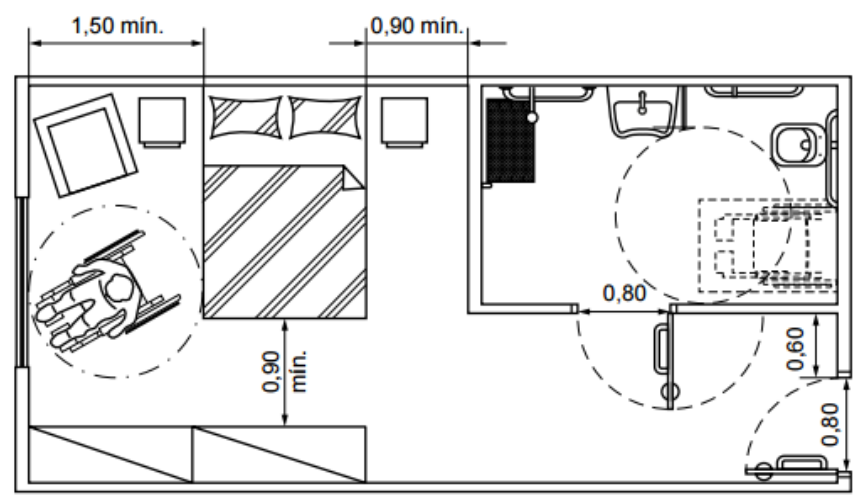

\subsection{Estudos de Caso}

\subsubsection{Edificação A}

A partir da análise do layout é possível verificar que apesar da sala de estar comportar o mobiliário mínimo recomendado pelo anexo G da ABNT NBR 15575 não permite uma circulação adequada para um cadeirante, ficando seu acesso restrito a cozinha, em virtude da localização da mesa de refeições.

As dimensões mínimas dos boxes de chuveiros não atendem a ABNT NBR 9050 quanto as dimensões de $0,90 \mathrm{~m} \times 0,95 \mathrm{~m}$ uma vez que no projeto foi construído com a largura de 70 $\mathrm{cm}$, porém a largura de $1,20 \mathrm{~m}$ do banheiro atende a NBR 15571 que recomenda largura mínima de 1,10m exceto para os boxes. Através da análise das dimensões do banheiro se observa a limitação de movimento para o cadeirante. 


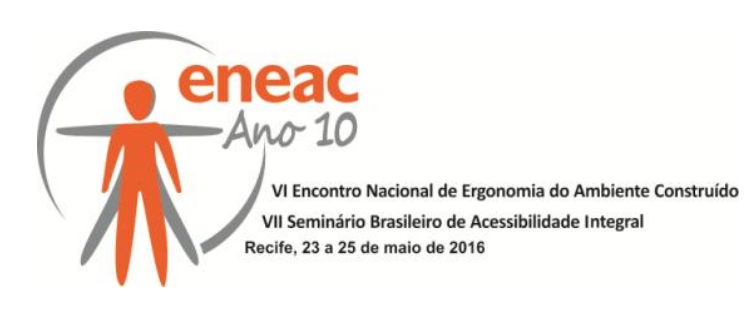

Nos quartos a recomendação da norma de desempenho não é atendida quanto a circulação mínima de $50 \mathrm{~cm}$, bem como mostra a dificuldade de acesso de um cadeirante ao guardaroupa conforme o layout.

\subsubsection{Edificação B}

Trata-se de edifícios de 4 pavimentos (térreo e 3 pavimentos tipos), sendo 4 unidades por pavimento tipo. Em cada bloco de apartamentos foi previsto um apartamento no térreo para portadores de necessidades especiais (PNE's), porém a diferença entre os apartamentos padrão foi apenas a largura da porta de entrada do apartamento para $90 \mathrm{~cm}$.

O apartamento atende de forma parcial a ABNT NBR 15575-1 devido o quarto 02 previsto para duas pessoas não comportar o mobiliário e a circulação mínima de 0,60 m entre as camas recomendados e o quarto de casal não atende a circulação mínima $0,50 \mathrm{~m}$ entre 0 mobiliário e/ou e/ou paredes de $0,50 \mathrm{~m}$. Para a mesa de quatro lugares a ABNT NBR 155751 recomenda circulação mínima de $0,75 \mathrm{~m}$ à partir da borda da mesa (espaço para afastar a cadeira e levantar) e dessa forma o projeto padrão não atende.

As dimensões mínimas dos boxes de chuveiros não atendem a ABNT NBR 9050 quanto as dimensões de $0,90 \mathrm{~m} \times 0,95 \mathrm{~m}$ uma vez que no projeto foi construído com a largura construída foi de $70 \mathrm{~cm}$, porém a largura de $1,20 \mathrm{~m}$ do banheiro atende a NBR 15571 que recomenda largura mínima de 1,10m exceto para os boxes.

Na própria ABNT NBR 15575-1 a recomendação para a circulação mínima de 0,85 m frontal à pia, fogão e geladeira no ambiente da cozinha, que tem largura mínima de 1,50 m, não comporta a largura mínima da geladeira de $70 \mathrm{~cm}$. Outra não conformidade refere-se quanto a área de giro de $360^{\circ}$ exigida para o cadeirante em um círculo de diâmetro de $1,50 \mathrm{~m}$ que não é obtida com a inserção do mobiliário.

\subsubsection{Edificação C}

Neste estudo de caso, as HIS previstas para PNEs foram projetadas com a redução da área do quarto de casal de forma a incluir o box do banheiro e atender a ABNT NBR 9050 (2004), porém ainda assim não atendeu as dimensões de 0,90 $\mathrm{m} \times 0,95 \mathrm{~m}$ uma vez foi projetado com as dimensões de $70 \mathrm{~cm} \times 100 \mathrm{~cm}$.

O Projeto atende de forma parcial a ABNT NBR 15575-1 devido o dormitório previsto para duas pessoas não comportar o mobiliário e a circulação mínima de 0,60 m entre as camas recomendados e o dormitório destinado para o casal não atende a circulação mínima 0,50 m entre o mobiliário e/ou paredes de $0,50 \mathrm{~m}$. A funcionalidade do quarto do casal foi comprometida devido a redução de sua área em prol do aumento das dimensões do banheiro.

\subsubsection{Edificação D}

O Projeto atende de forma parcial a NBR 15575-1 devido a mesa de quatro lugares não atender a circulação mínima de $0,75 \mathrm{~m}$ à partir da borda da mesa (espaço para afastar a cadeira e levantar). Assim como na edificação $B$, a edificação $C$ não atende a recomendação para a circulação mínima de $0,85 \mathrm{~m}$ frontal à pia, fogão e geladeira no ambiente da cozinha, que tem largura mínima de 1,50 m, não comporta a largura mínima da geladeira de $70 \mathrm{~cm}$. Outra não conformidade refere-se quanto a área de giro de $360^{\circ}$ exigida 


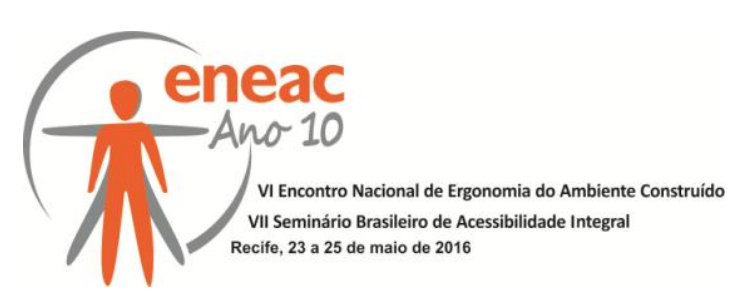

para o cadeirante em um círculo de diâmetro de 1,50m que não é obtida com a inserção do mobiliário.

O projeto padrão da Caixa Econômica Federal não prevê um ambiente de refeição para o posicionamento de uma mesa com as dimensões mínimas recomendadas pela ABNT NBR 15575-1 e dessa forma o Projeto apresenta falhas de concepção.

As dimensões mínimas dos boxes de chuveiros não atendem a NBR 9050 quanto as dimensões de $0,90 \mathrm{~m} \times 0,95 \mathrm{~m}$ uma vez que no projeto foi construído com a largura construída foi de $70 \mathrm{~cm}$, porém a largura de 1,10 m do banheiro atende a NBR 15571 .

\subsubsection{Edificação E}

O Projeto E é uma concepção do Programa Minha Casa Minha vida e tem o sistema construtivo inovador, no qual as paredes são executadas com concreto armado de $10 \mathrm{~cm}$, a fundação em radier e laje executada em concreto armado coberta com telha de amianto. $O$ pé direito da casa é de 2,60 $\mathrm{m}$.

As dimensões do banheiro atende a ABNT NBR 9050 (2004), porém o lavatório fica localizado em área de circulação.

Se observa que as dimensões dos ambientes atendem o mobiliário mínimo do Anexo $G$ da ABNT NBR 15575-1, porém quando o morador da HIS for um cadeirante o desempenho quanto a funcionalidade e acessibilidade não serão atendidos.

Figura 2 - Layout Edificação A

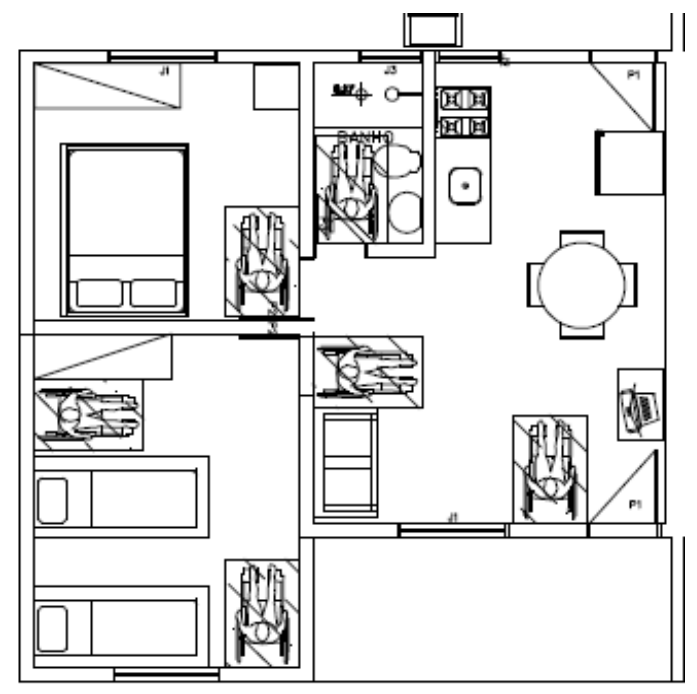

Figura 3 - Layout Edificação B

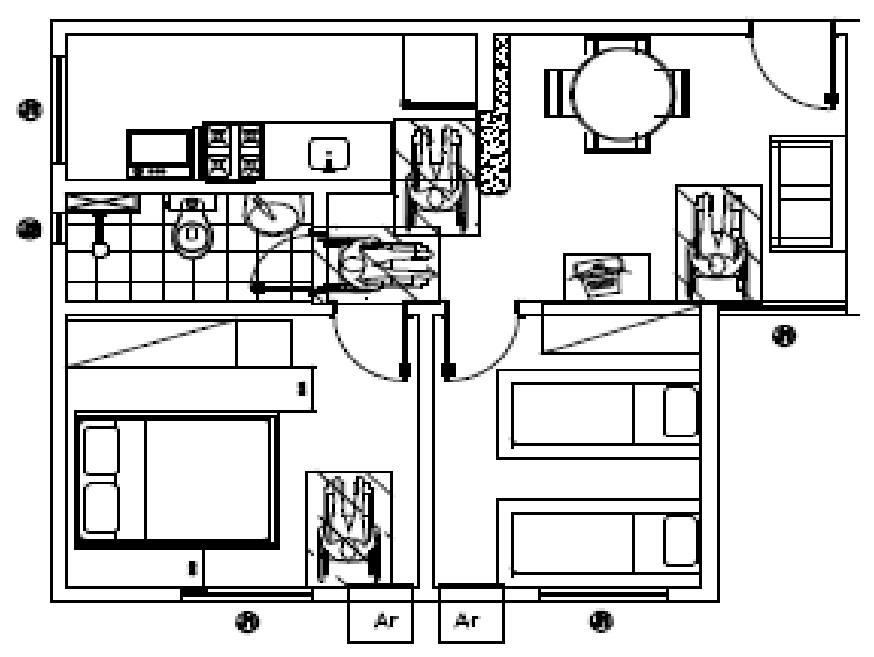




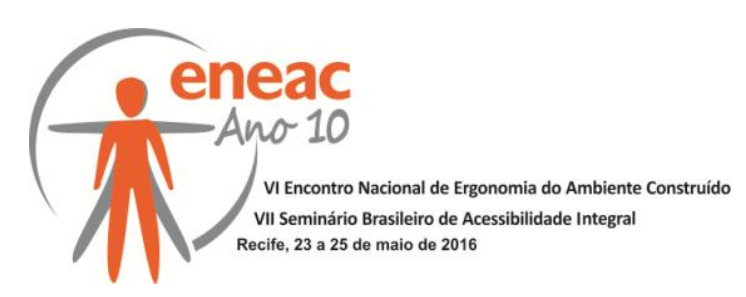

Figura 4 - Layout Edificação C

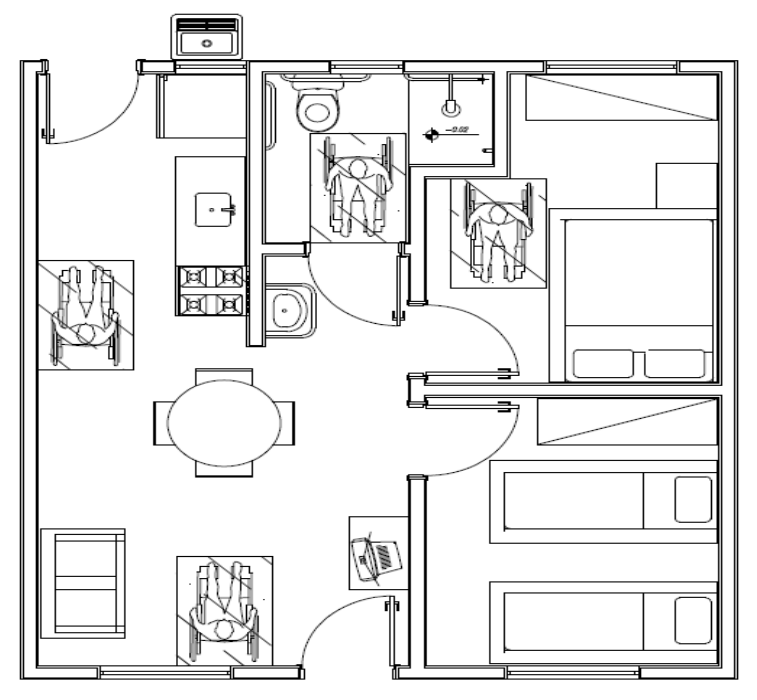

Figura 5 - Layout Edificação D

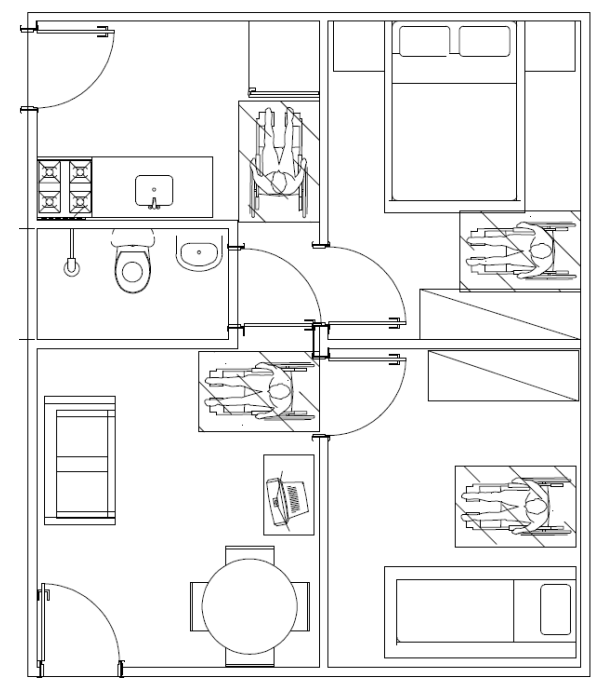

Figura 6 - Layout Edificação E

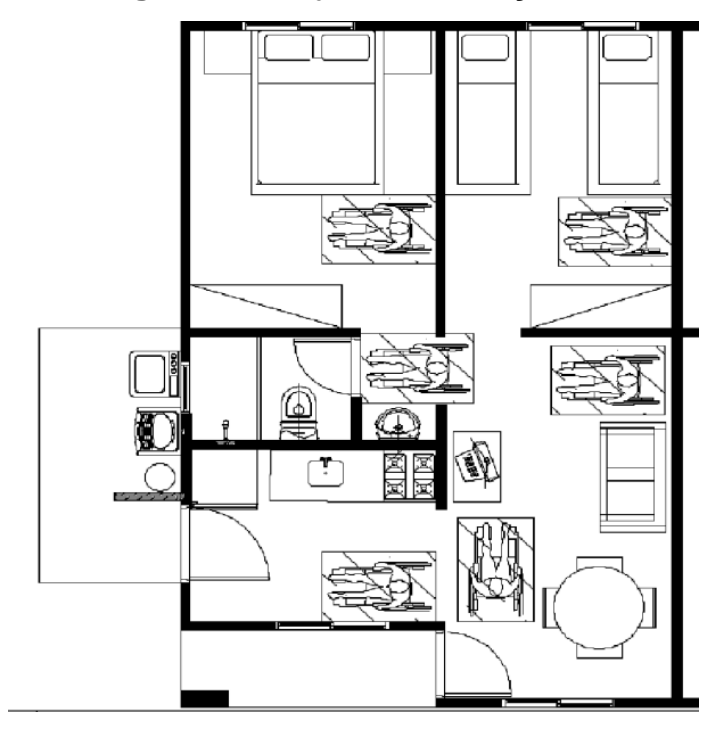




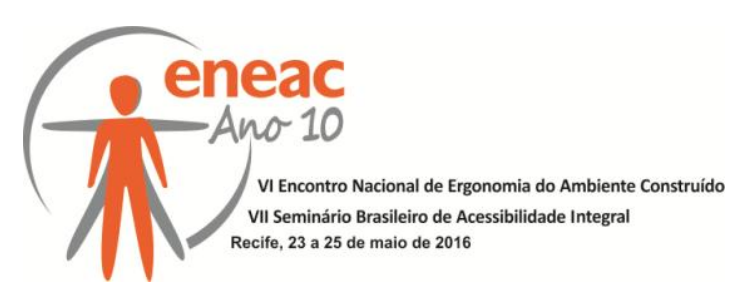

Tabela 3 - Check List

\begin{tabular}{|c|c|c|c|c|c|c|}
\hline \multirow{2}{*}{ Ambiente } & \multirow{2}{*}{ Requisitos } & \multicolumn{5}{|c|}{ Conformidade } \\
\hline & & A & B & C & D & $\mathbf{E}$ \\
\hline \multirow{3}{*}{ Sala de Estar } & $\begin{array}{c}\text { Espaço de } 0,50 \mathrm{~m} \text { na frente do } \\
\text { assento }\end{array}$ & C & C & C & C & C \\
\hline & Largura mínima de 2,40 m & C & C & C & C & C \\
\hline & $\begin{array}{l}\text { Espaço obrigatório para estante ou } \\
\text { armário para TV }\end{array}$ & C & C & C & C & C \\
\hline $\begin{array}{l}\text { Sala } \\
\text { estar/jantar }\end{array}$ & $\begin{array}{l}\text { Circulação mínima de } 0,75 \mathrm{~m} \text { à } \\
\text { partir da borda da mesa }\end{array}$ & NC & NC & NC & NC & NC \\
\hline $\begin{array}{c}\text { Sala de } \\
\text { jantar/copa } \\
\text { Copa/cozinha }\end{array}$ & Largura mínima de 2,40 m & C & C & C & C & C \\
\hline \multirow{3}{*}{ Cozinha } & $\begin{array}{c}\text { Circulação mínima } 0,85 \text { m frontal à } \\
\text { pia, fogão e geladeira }\end{array}$ & C & NC & C & NC & C \\
\hline & Largura mínima da cozinha: $1,50 \mathrm{~m}$ & C & C & C & C & C \\
\hline & $\begin{array}{c}\text { Espaço obrigatório para armário } \\
\text { sob a pia e gabinete }\end{array}$ & C & C & C & C & C \\
\hline $\begin{array}{c}\text { Dormitório } \\
\text { casal } \\
\text { (dormitório } \\
\text { principal) }\end{array}$ & $\begin{array}{l}\text { Circulação mínima entre o } \\
\text { mobiliário e/ou paredes de } 0,50 \mathrm{~m}\end{array}$ & NC & NC & NC & C & C \\
\hline \multirow{2}{*}{$\begin{array}{l}\text { Dormitório } \\
\text { para } 2 \\
\text { pessoas }\end{array}$} & $\begin{array}{l}\text { Circulação mínima entre as camas } \\
\text { de } 0,60 \mathrm{~m}\end{array}$ & C & NC & NC & C & C \\
\hline & $\begin{array}{l}\text { Demais circulações: mínimo de } \\
\qquad 0,50 \mathrm{~m}\end{array}$ & C & NC & NC & - & C \\
\hline \multirow{4}{*}{ Banheiro } & $\begin{array}{l}\text { Circulação mínima de } 0,4 \mathrm{~m} \text { frontal } \\
\text { ao vaso, lavatório e bidê }\end{array}$ & C & C & C & C & C \\
\hline & $\begin{array}{l}\text { Largura mínima do banheiro } 1,10 \\
\text { m, exceto no box }\end{array}$ & C & C & C & C & C \\
\hline & Box Quadrado: 0,8 x 0,8 m & - & - & - & - & - \\
\hline & Box Retangular: $0,7 \times 0,9 \mathrm{~m}$ & C & C & C & C & C \\
\hline $\begin{array}{l}\text { Área de } \\
\text { Serviço }\end{array}$ & $\begin{array}{c}\text { Circulação Mínima de } 0,50 \mathrm{~m} \\
\text { frontal ao tanque e máquina de } \\
\text { lavar }\end{array}$ & C & C & c & c & C \\
\hline
\end{tabular}




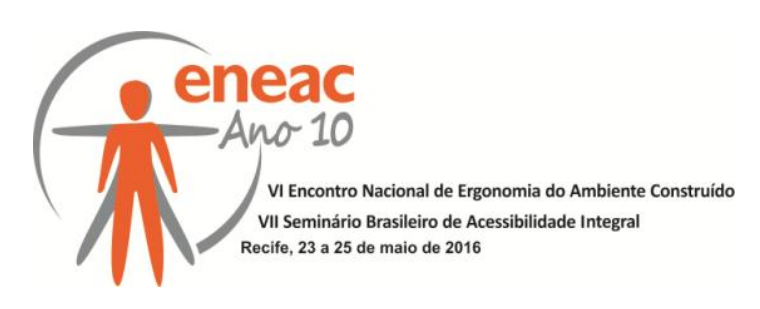

\section{CONCLUSÕES}

A moradia é um direito básico de qualquer cidadão. Em sua residência o morador deve exercer todas as suas atividades com segurança e conforto. Porém, como foi mostrado nos estudos de caso, os cadeirantes não possuem o espaço mínimo necessário para se locomover por todos os cômodos, sendo a situação mais crítica nas áreas de boxes dos banheiros e na cozinha. Foi constatado que os espaços entre os móveis, que possuíam as mínimas dimensões previstas pelo anexo G da NBR 15575-1, não são suficientes para a passagem da cadeira de rodas. Os ambientes não possibilitam fazer manobras com deslocamento e muitas vezes sem deslocamento também.

A aplicação do check list apresentado e cumprimento de todos os itens listados não garante ao cadeirante boas condições de funcionalidade e acessibilidade na edificação, pois notouse uma incompatibilidade entre a norma de desempenho e as recomendações definidas na ABNT NBR 9050, já que esta última está mais voltada para a adaptação de áreas públicas. O código de obras da cidade traz como recomendação normativa a norma de desempenho e as recomendações desta não garante áreas de circulação adequadas para os cadeirantes.

Os espaços de circulação entre os móveis, que possuíam as mínimas dimensões previstas pelo anexo G da NBR 15575-1, não são suficientes para a passagem da cadeira de rodas. Existe falta de interesse do mercado imobiliário para fornecer equipamentos necessários a fim de garantir a acessibilidade e a independência do cadeirante nas HIS, e assim, o presente estudo indica as seguintes ações:

- Elaboração de referência normativa que estabeleça dimensões mínimas de ambientes e áreas de circulação para ambientes privativos, visando a acessibilidade e funcionalidade nos projetos de edificações para pessoas cadeirantes, baseados no conceito do desenho universal presente no anexo A da ABNT NBR 9050 - 2015, possibilitando ao usuário autonomia em sua habitação;

- O aprofundamento nos estudos voltados para a adaptação da habitação de interesse social para as diversas necessidades e habilidades do seu público-alvo, uma vez que as habitações em estudo oferecem pouca ou nenhuma possibilidade de adaptação.

- Os projetos devem possibilitar acesso e circulação compatíveis com a cadeira de rodas, livres de barreiras e obstáculos, espaços capazes de receber o mobiliário proposto e que a distribuição espacial dos equipamentos não prejudique circulações, acessos ou mesmo o uso destes e prever soluções mais generosas de ligação interior e exterior de ambientes, uma vez que elas contribuem significativamente para a qualidade ambiental e psicológica do espaço e que, no caso de cadeirantes, são de grande importância. 


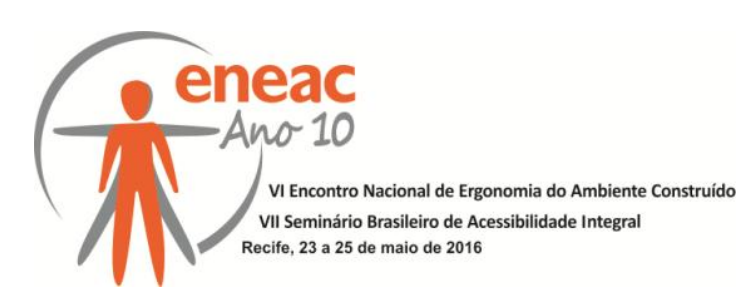

\section{REFERÊNCIAS BIBLIOGRÁFICAS}

ASSOCIAÇÃO BRASILEIRA DE NORMAS TÉCNICAS, NBR 9050: Acessibilidade a edificações, mobiliário, espaços e equipamentos urbanos. Rio de Janeiro, 2015.

ASSOCIAÇÃO BRASILEIRA DE NORMAS TÉCNICAS, NBR 15575-1: Edificações Habitacionais Desempenho. Requisitos Gerais. Rio de Janeiro, 2013.

CALDAS, L.R.; MOREIRA, M.M; SPOSTO, R.M. Acessibilidade para Pessoas com Mobilidade Reduzida Segundo os Requisitos da Norma de Desempenho - Um Estudo de Caso para as Áreas Comuns de Edificações Habitacionais de Brasília - DF. Revista Eletrônica de Engenharia Civil - UFG. Volume 10. № 2 (2015)

CAMARA BRASILEIRA DA INDÚSTRIA DA CONSTRUÇÃO (CBIC). Desempenho de edificações habitacionais. Guia orientativo para atendimento a NBR 15575. Brasília, 2013.

CÓDIGO DE OBRAS. Código de Obras e Edificações do Município de Porto Velho. Lei Complementar № 560 de 23 de dezembro de 2015.

DAMÉ, L.M. Habitação PAR, Desempenho Ímpar?Uma Avaliação Funcional de Unidades Multifamiliares em Pelotas/RS. Dissertação de mestrado apresentada ao Programa de PósGraduação em Arquitetura e Urbanismo. Universidade Federal de Santa Catarina.Florianópolis, Santa Catarina, 2008.

FREGOLENTE, R. Caracterização da Acessibilidade em Espaços Públicos. A Ergonomia e o Desenho Universal Contribuindo Para a Mobilidade de Pessoas Portadoras de Necessidades Especiais. Estudo de Caso. Dissertação (Mestrado em Design). Faculdade de Arquitetura, Artes e Comunicação. Universidade Estadual Paulista. 169p. Bauru, 2008.

GOOGLE MAPS. Disponível: <https://www.google.com.br/maps?source=tldsi\&hl=en> Acesso em: $01 / 11 / 2015$.

LEÃO, A.R. O Impacto do Padrão de Moradia Popular para Acessibilidade no Modo de Vida dos Moradores. Dissertação apresentada ao Curso de Mestrado da Escola de Arquitetura da Universidade Federal de Minas Gerais. Belo Horizonte, Minas Gerais, 2011.

MARTINS, D.N.; OLIVO, A.A.; MARTINS, A.R.I. Avaliação da qualidade da solução de arranjos físicos de habitações com áreas mínimas, a partir de variáveis geométricas de projeto.Curso de Graduação em Arquitetura e Urbanismo, Universidade Estadual de Maringá, Maringá, Paraná, Brasil.2007.

Portaria no 595, de 18 de dezembro de 2013, que dispõe sobre os parâmetros de priorização e sobre o processo de seleção dos beneficiários do Programa Minha Casa, Minha Vida - PMCMV. Ministérios das Cidades. Brasil. 